\title{
Delayed onset acute massive haemothorax after traumatic rib fractures- A case report
}

\author{
Wael Hassan ${ }^{1}$
}

\section{Abstract}

Rib fractures are common injuries that frequently necessitate intensive care admission for pain management, respiratory support, in addition to managing possible complications. The most common complications of rib fractures are pain, haemothorax, pneumothorax, pulmonary contusions and lacerations, vascular injuries, and intra-abdominal organ injury.

After a high impact road traffic accident, a polytrauma 26-year-old Irish gentleman presented with right-sided posterior rib series fractures (from $8^{\text {th }}$ to $12^{\text {th }}$ rib), lung contusion, hepatic laceration, pelvic ring crush injury and urinary bladder disruption. Resuscitation and emergency management including suprapubic catheterisation and external pelvic fixation were performed successfully. Although complications of multiple rib fractures were excluded clinically and radiologically on admission, the patient developed acute massive haemothorax 5 days after the primary injury which has been managed appropriately.

This incident raises the concern that haemothoraces and pneumothoraces can occur late after the original injury and high level of suspicion associated with follow-up chest $\mathrm{x}$-ray images are essential in patients with rib fractures.

Keywords: polytrauma, rib fracture, haemothorax

\section{Introduction}

$\mathrm{Rib}$ fractures are common injuries that occur in up to $10 \%$ of polytrauma patients, often following blunt chest trauma. They usually increase the risk of morbidity and mortality of trauma patients, and frequently necessitate intensive care admission for pain management and respiratory support [1].

Flail chest is defined as fracture of more than two adjacent ribs in two places creating one unstable segment. This segment usually exhibits paradoxical movement with breathing and is often associated with significant injuries.

Performing Chest X-ray for trauma patients, especially those with symptoms or signs of rib fractures, may identify the fractured ribs and exclude any possible life threatening complication such as pneumothorax or haemothorax.

The most common complications of rib fractures are pain, haemothorax, pneumothorax, pulmonary contusions and lacerations, vascular injuries, and intra-abdominal organ injury. Specific structure injury could be correlated with certain rib fractures. First rib fracture is usually related to severe type of trauma and can cause injury to subclavian vessels. Brachial plexus injury and disruption of mediastinum including aorta are linked to first to third rib fractures. Liver and spleen are commonly associated with $9^{\text {th }}$ to $12^{\text {th }}$ rib fractures on corresponding sides [2].

\section{Case Report}

A 26-year-old Irish gentleman was brought to emergency department by ambulance after a high impact frontal car collision while he was on the driver car seat with the seat belt on. He had mild disturbed level of consciousness with Glasgow Coma Scale (GCS) of $14 / 15$ and was maintaining his airway. He was tachycardic $(130 /$ minute $)$ and hypotensive $(80 / 50 \mathrm{mmHg})$ with tender abdomen and pelvis and responded to fluid and blood resuscitation. Chest X-ray (CXR) did not show any signs of haemo or pneumothorax (Figure1). CT revealed right-sided posterior rib series fractures (from $8^{\text {th }}$ to $12^{\text {th }} \mathrm{rib}$ ), moderate right lung contusion, hepatic laceration, pelvic ring crush injury and urinary bladder disruption. Suprapubic catheter was inserted, and pelvic external fixation was performed after stabilisation of general condition.

After 4-days stay in ICU under observation, monitoring and managing pain, the patient was transferred to the orthopaedic ward in preparation to transfer him to the regional trauma centre for definitive pelvic fixation. CXR was done before transfer and showed mild right pleural effusion (Figure2). 1 day later, the patient started to complain of worsening pain on his right side of chest which was managed accordingly using morphine PCA in addition to simple oral analgesics. CXR at this stage showed picture of mild to moderate right sided pleural effusion (Figure3). Few

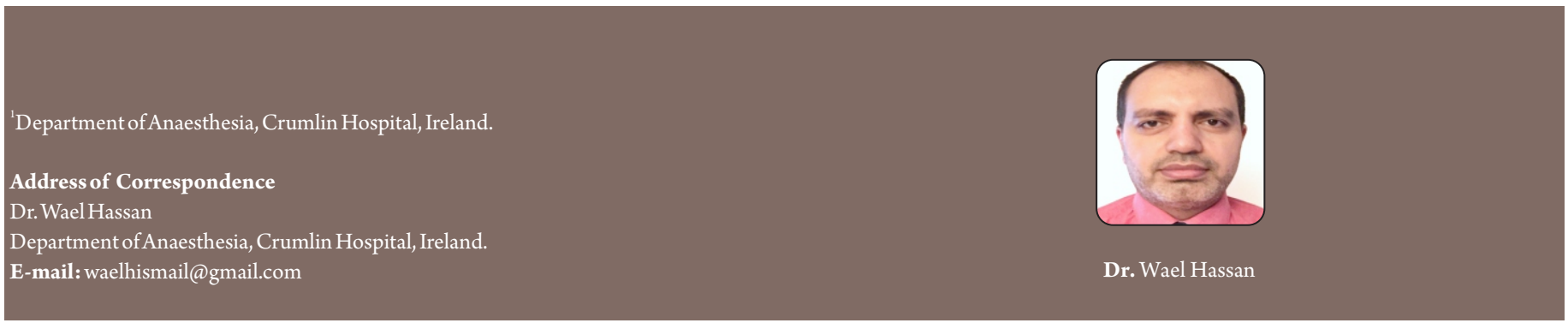

Submitted: 7 February 2020; Reviewed: 28 April 2020; Accepted: 12 January 2021; Published: 10 May 2021

This is an Open Access article distributed under the terms of the Creative Commons Attribution Non-Commercial-Share Alike 4.0 License (http://creativecommons.org/licenses/by-nc-sa/4.0) which allows others to remix, tweak, and build upon the work non-commercially as long as appropriate credit is given and the new creation are licensed under the identical terms. 

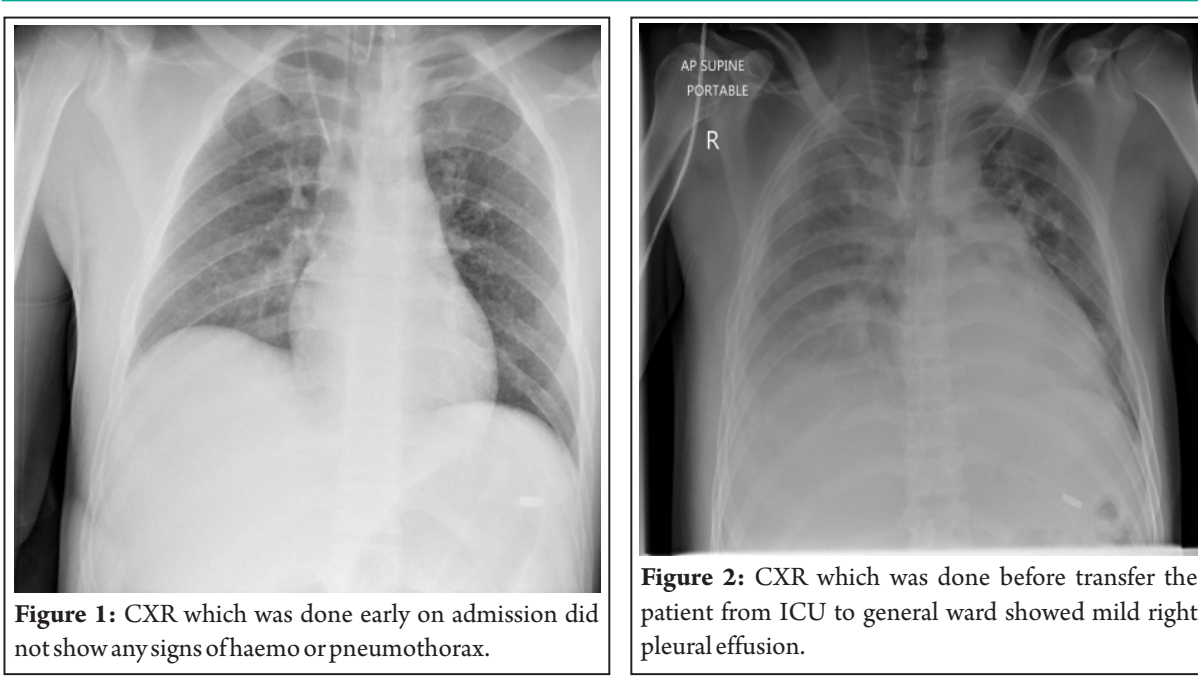

Figure 2: CXR which was done before transfer the patient from ICU to general ward showed mild right pleural effusion.

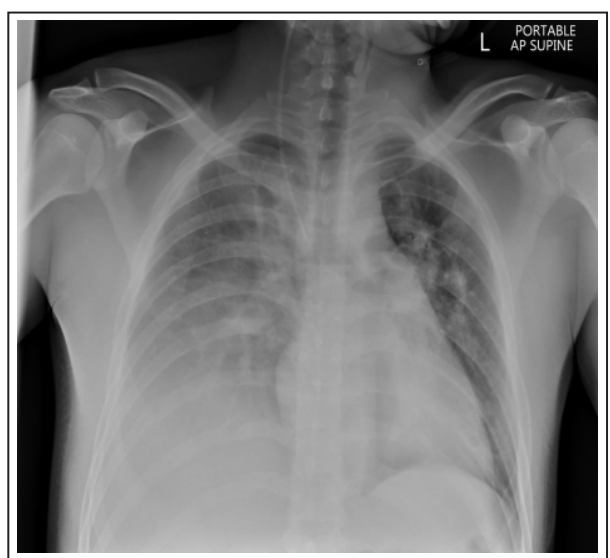

Figure 3: CXR, which was done when the patient started to complain of worsening right chest pain, showed picture of mild to moderate right sided pleural effusion. hours later, the patient started to show signs of shock with agitation, cold clammy skin, rapid weak pulse (140/min.), tachypnoea $(40 / \mathrm{min}$.) and hypotension $(80 / 45 \mathrm{mmHg})$. Right side of chest showed reduced expansion, dullness on percussion and absence of breath sounds. CXR showed picture of massive right sided haemothorax (Figure 4). Emergency management was initiated; including $100 \% \mathrm{O}_{2}$, right chest tube drainage (Figure 5), along with fluid and blood resuscitation. A volume of $1600 \mathrm{mls}$ of blood was drained from right chest immediately and another litre was drained over few more hours.

After stabilisation, the patient was transferred to the regional thoracic surgery hospital where he was managed conservatively without the need of any surgical intervention.

\section{Discussion}

Thoracic trauma comprises the majority of trauma cases requiring hospital admission, with high-speed vehicle accidents being its main cause. Around one third of chest trauma cases suffer from rib fractures [3].

Many patients with rib fractures present with other traumatic thoracic injury complications such as hemothorax, pneumothorax and lung contusion which could be diagnosed late after primary injury [4].

Patients can often localize their pain over the exact area of rib fracture that is usually being exacerbated by taking a deep breath.
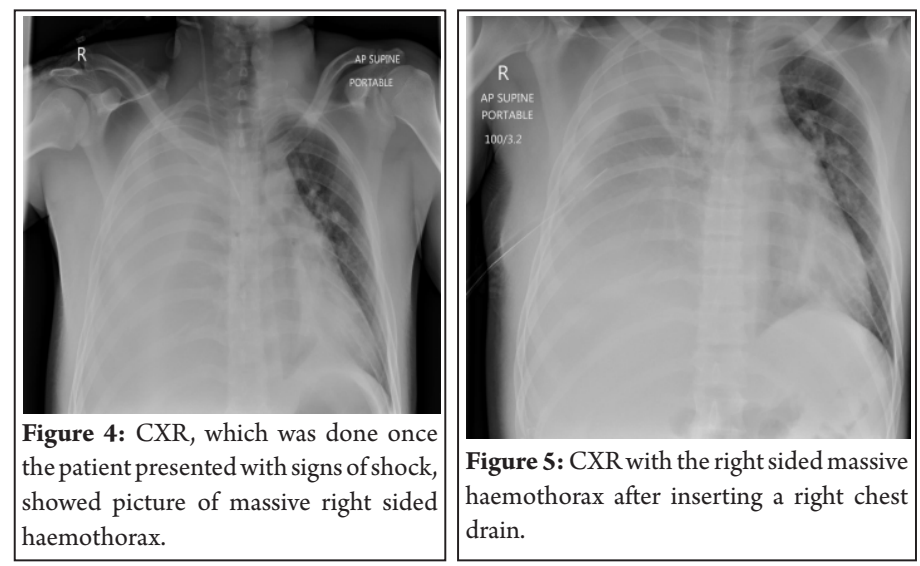

Examination findings may include localised tenderness, bony crepitus and ecchymosis. Diminished breath sounds on auscultation may be due to splinting as a result of pain or may be due to more dangerous complications such as pneumothorax, hemothorax, or pulmonary contusion.

Delayed massive haemothorax can occur as a result of tearing of intercostal or phrenic vessels or diaphragmatic injury by the sharpedged fractured ribs [5]. As the patient starts to move and sit up, increased intraabdominal pressure leads to approximation of the diaphragmtic dome to the edge of fractured rib, leading to laceration of diaphragm and intrathoracic bleeding [6].

Although delayed onset traumatic haemothorax would be considered rare in its occurrence after rib fractures, early diagnosis and prompt management are essential for favourable outcome [7]. Follow-up chest x-ray images including one before discharge are essential in patients with rib fractures, as both haemothoraces and pneumothoraces can occur late after the original injury [8]. Acute massive haemothorax primarily necessitates evacuation of the blood accumulating in the thoracic cavity along with resuscitating patient with blood transfusion. Some cases may require surgical control of persistent bleeding either via thoracoscopic surgery or open thoracotomy [5].

\section{Conclusion}

This incident raises the concern that haemothoraces and pneumothoraces can occur late after the original injury in patients presenting with rib fractures. A high level of suspicion associated with follow-up chest X-ray images are essential in successful management of those patients.

In our case, early diagnosis and prompt emergency management have led to favourable outcome of our patient's condition. 
Declaration of patient consent: The authors certify that they have obtained all appropriate patient consent forms. In the form, the patient has given his consent for his images and other clinical information to be reported in the Journal. The patient understands that his name and initials will not be published, and due efforts will be made to conceal his identity, but anonymity cannot be guaranteed.

\section{Conflict of interest: Nil Source of support: None}

\section{References}

1. Pressley C, Fry W, Philp A, Berry S, Smith R. Predicting outcome of patients with chest wall injury. Am J Surg 2012; 204:910-4.

2. Talbot B.S., Gange C.P., Chaturvedi A., Klionsky N., Hobbs S.K., and Chaturvedi A.: Traumatic rib injury: patterns, imaging pitfalls, complications, and treatment. Radiographics 2017 Mar-Apr; 37: 628-651.

3. Demirhan R, Onan B, Oz K, et al. Comprehensive analysis of 4205 patients with chest trauma: a 10-year experience. Interactive CardioVascular and Thoracic Surgery. Sept. 2009; 9(3): 450-453.

4. Al-Koudmani I, Darwish B, Al-Kateb K, et al. Chest trauma experience over eleven-year period at al-mouassat university teaching hospital-Damascus: a retrospective review of 888 cases.J Cardiothorac Surg. 2012;7:35.
5. Chang SW, Ryu KM, Ryu JW. Delayed massive hemothorax requiring surgery after blunt thoracic trauma over a 5-year period: complicating rib fracture with sharp edge associated with diaphragm injury. Clin Exp Emerg Med.2018;5:60-5.

6. Igai H, Kamiyoshihara M, Yoshikawa R, et al. Delayed massive hemothorax dye to diaphragmatic laceration caused by lower rib fractures. Gen. Thorac. Cardiovasc. Surg.2018.https://doi.org/10.1007/s11748-018-1033-8.

7. Sharma OP, Hagler S, Oswanski MF. Prevalence of delayed hemothorax in blunt thoracic trauma. Am Surg 2005; 71:481-6.

8. Brasel KJ, Moore EE, Albrecht RA, et al. Western Trauma Association Critical Decisions in Trauma: Management of Rib Fractures.J Trauma Acute Care Surg. Jan. 2017; 82(1):200-203.

\section{How to Cite this Article}

Hassan W | Delayed onset acute massive haemothorax after traumatic rib fractures: A case report | Journal of Anaesthesia and Critical Care Case Reports | May-August 2021; 7(2): 14-16. 